\title{
Linking ITCZ Migrations to the AMOC and North Atlantic/Pacific SST Decadal Variability 0
}

\author{
E. MORENO-ChAMARROa AND J. MARSHALL \\ Department of Earth, Atmospheric, and Planetary Sciences, Massachusetts Institute of Technology, Cambridge, Massachusetts
}

\section{T. L. DELWORTH}

NOAA/Geophysical Fluid Dynamics Laboratory, Princeton, New Jersey

(Manuscript received 4 April 2019, in final form 17 October 2019)

\begin{abstract}
We examine the link between migrations in the intertropical convergence zone (ITCZ) and changes in the Atlantic meridional overturning circulation (AMOC), Atlantic multidecadal variability (AMV), and Pacific decadal oscillation (PDO). We use a coupled climate model that allows us to integrate over climate noise and assess underlying mechanisms. We use an ensemble of ten 300-yr-long simulations forced by a 50-yr oscillatory North Atlantic Oscillation (NAO)-derived surface heat flux anomaly in the North Atlantic, and a 4000yr-long preindustrial control simulation performed with GFDL CM2.1. In both setups, an AMV phase change induced by a change in the AMOC's cross-equatorial heat transport forces an atmospheric interhemispheric energy imbalance that is compensated by a change in the cross-equatorial atmospheric heat transport due to a meridional ITCZ shift. Such linkages occur on decadal time scales in the ensemble driven by the imposed forcing, and internally on multicentennial time scales in the control. Regional precipitation anomalies differ between the ensemble and the control for a zonally averaged ITCZ shift of similar magnitude, which suggests a dependence on time scale. Our study supports observational evidence of an AMV-ITCZ link in the twentieth century and further links it to the AMOC, whose long-time-scale variability can influence the phasing of ITCZ migrations. In contrast to the AMV, our calculations suggest that the PDO does not drive ITCZ migrations, because the PDO does not modulate the interhemispheric energy balance.
\end{abstract}

\section{Introduction}

The strong moisture convergence in the lower branch of the Hadley circulation sets the position of the intertropical convergence zone (ITCZ), a narrow band of intense precipitation that encircles Earth near the equator. The meridional position of the zonally averaged Hadley circulation and ITCZ is tied to the atmospheric energy balance between the Northern and Southern Hemispheres (NH and $\mathrm{SH}$, respectively) (e.g.,

Supplemental information related to this paper is available at the Journals Online website: https://doi.org/10.1175/JCLI-D-190258.s1.

\footnotetext{
${ }^{\text {a }}$ Current affiliation: Barcelona Supercomputing Center, Barcelona, Spain.
}

Corresponding author: E. Moreno-Chamarro, eduardo.moreno@ bsc.es
Chiang and Friedman 2012; Schneider et al. 2014). In the present-day climate the $\mathrm{NH}$ is heated more strongly than the $\mathrm{SH}$ in the annual mean [as described in Frierson et al. (2013) and Marshall et al. (2014)]. To compensate for this imbalance, the Hadley circulation-the main driver of atmospheric meridional energy transport in the tropics-and the ITCZ are centered north of the equator, thus allowing a net southward atmospheric energy transport across the equator. Over the seasonal cycle the Hadley circulation and the ITCZ migrate meridionally following the solar-driven heating imbalance, transporting energy into the colder, winter hemisphere (e.g., Donohoe et al. 2013). On longer time scales, a variety of modeling studies have shown that the Hadley cells shift meridionally as a result of atmospheric heating imbalances driven by changes in the Atlantic Ocean heat transport (Vellinga and Wu 2004; Zhang and Delworth 2005; Broccoli et al. 2006; Sun et al. 2013; Frierson et al. 2013; Marshall et al. 2014) or Arctic ice cover (Chiang and Bitz 2005), as well as in future global warming 
scenarios (Frierson and Hwang 2012). Paleoclimate proxy records also suggest that strong $\mathrm{NH}$ cooling is linked to a southward shift of the Hadley circulation and ITCZ during Heinrich and Dansgaard-Oeschger events (e.g., Chiang and Friedman 2012; McGee et al. 2014, 2018a). In observations over the twentieth century, the ITCZ position appears to be connected to an interhemispheric heating imbalance driven by multidecadal variability in the extratropical sea surface temperature (SST) of the North Atlantic [Atlantic multidecadal variability (AMV)] (Green et al. 2017). Yet, whether this link can ultimately be extended to AMOC multidecadal variability is difficult to answer with the inadequate observational record. Moreover, observational estimates disagree on the influence of the North Pacific SST multidecadal variability [Pacific decadal oscillation (PDO)] on the ITCZ position (Green et al. 2017) and the potential linking mechanisms. Here, we therefore use a climate model to explore the connection between the AMOC, North Pacific, and Atlantic SST variability characterized by the AMV and PDO, respectively, and the ITCZ meridional position.

The AMV is a same-signed, basin-scale, multidecadal fluctuation of the North Atlantic SST that has been observed in the twentieth century and is superimposed on the long-term warming trend (Kerr 2000). Phase changes of the AMV impact global tropical precipitation, especially in the West African and East Asian monsoon regions as well as the ITCZ position (e.g., Folland et al. 2001; Zhang and Delworth 2006; Mohino et al. 2011; Ruprich-Robert et al. 2017). ITCZ migrations have been connected to the interhemispheric heating contrast associated with North Atlantic SST anomalies, which warm or cool the entire $\mathrm{NH}$ troposphere with respect to the $\mathrm{SH}$ (e.g., Green et al. 2017). Since the AMV has a causal link to multidecadal variability in the AMOC's northward heat transport [as reviewed in Buckley and Marshall (2016)], multidecadal ITCZ variability might, by extension, also be linked to AMOC variability, which offers a window for improved predictability of ITCZ migrations via AMOC predictability (Tulloch and Marshall 2012).

The PDO is a multidecadal fluctuation of the tropical and midlatitude North Pacific SSTs that presents colder central North Pacific SSTs and warmer SSTs along the American west coast during its positive phase, and vice versa (Mantua et al. 1997). The PDO has been attributed to midlatitude ocean-atmosphere feedbacks relating the Aleutian low and surface winds over the North Pacific [as reviewed in Liu (2012) and Newman et al. (2016)]. Although the PDO has been connected to tropical precipitation changes over Central America, northern South America, western Australia, southern India, and central Africa (Mantua and Hare 2002), it is poorly correlated with ITCZ shifts over the twentieth century (Green et al. 2017). This is perhaps because interhemispheric heating differences are unlikely to arise from changes in the Pacific Ocean heat transport, which is smaller than in the Atlantic (Trenberth and Caron 2001) and characterized by shallow wind-driven meridional circulation cells (Ferrari and Ferreira 2011). Thus, the ITCZ-PDO connection seems rather tenuous, at least as revealed by the observational record.

Better understanding of the potential connections between variability of the AMOC, AMV, PDO, and ITCZ is of key importance, given the huge impact of tropical precipitation distribution on the billions of people who live in the tropics. In this study, therefore, we explore the links of AMV, AMOC, and PDO with ITCZ position, and whether they are robust in time and across time scales in a climate model. Two different experimental setups are explored, which present different AMV characteristics. Our analysis will help assess and lend support to recent conclusions drawn from observations over the twentieth century.

The structure of the paper is as follows: the model and experimental setups are described in section 2. Section 3 documents the main results of the climate model simulations. A discussion of the key results and the main conclusions follow in sections 4 and 5 respectively.

\section{Model description and experimental setup}

We use the GFDL CM2.1 coupled climate model, which consists of atmosphere, ocean, land, and sea ice components. The atmospheric model has a $2.5^{\circ} \times 2^{\circ}$ horizontal resolution and 24 vertical levels. The ocean model has a nominal horizontal resolution of $1^{\circ}$ in the extratropics, with the meridional grid spacing in the tropics gradually decreasing to a minimum of $1 / 3^{\circ}$ near the equator, and 50 vertical levels, with 22 evenly spaced levels in the top $220 \mathrm{~m}$. The model does not use flux adjustments. A more detailed description of the model is given in Delworth et al. (2006). This model has been used in multiple studies of climate variability, predictability, and change. A comprehensive model output from previous studies is available at https://nomads.gfdl.noaa. gov/CM2.X/.

Our analysis is based on two types of simulations with the same model. We first use a 300 -yr-long ensemble of 10 members that are forced by a surface heat flux anomaly derived from regressing reanalysis oceanatmosphere heat flux anomalies onto the winter North Atlantic Oscillation (NAO) index (Delworth and Zeng 2016). The forcing is added as an additional flux component to the normally computed air-sea heat flux, but only in the Atlantic sector, from the equator to $82^{\circ} \mathrm{N}$, including the Barents and Nordic seas. The forcing 
anomaly is computed ensuring its areal integral is zero and thus does not provide a net heating or cooling to the climate system. The amplitude of the added NAO heat flux is modulated sinusoidally in time with a single period of 50 years and an amplitude of one standard deviation. For a more detailed description of how these simulations were designed we refer to Delworth and Zeng (2016). We next use a 4000-yr-long preindustrial control simulation in which all forcings are kept constant at 1860 conditions. The simulated period excludes the spinup phase previous to it. This simulation is described in detail in Delworth and Zeng (2012), where the authors investigate the link between multicentennial variability (time scale of 200-500 years) in the AMOC and its associated cross-equatorial heat transport and $\mathrm{NH}$ extratropical temperatures. In contrast to the ensemble, this calculation simulates a long control climate with unforced internal variability and thus provides a different framework to investigate the connection between the ITCZ and the AMV, AMOC, and PDO.

We define indices for the ITCZ position, AMV, AMOC strength, interhemispheric temperature difference, and PDO. The ITCZ position (Pcent) is defined as the latitude that divides regions of equal zonally averaged, annual mean total precipitation between $20^{\circ} \mathrm{S}$ and $20^{\circ} \mathrm{N}$ (i.e., the centroid), as in Donohoe et al. (2013). The AMV index is the difference between the average North Atlantic SST and the global SST in the annual mean, following Trenberth and Shea (2006). The AMOC strength is calculated as the annual mean overturning circulation averaged between $35^{\circ}$ and $45^{\circ} \mathrm{N}$ at $1000-\mathrm{m}$ depth (corresponding to the position of the climatological maximum of the overturning cell; not shown). The interhemispheric temperature contrast is the difference between the $\mathrm{NH}$ and $\mathrm{SH}$ annual mean atmospheric temperature averaged between the surface and $300 \mathrm{hPa}$ from the equator to the pole. The PDO index is the first principal component of the undetrended annual mean SST over the North Pacific Ocean between $20^{\circ}$ and $70^{\circ} \mathrm{N}$ (Mantua et al. 1997; Newman et al. 2016). All the indices are linearly detrended after they are computed. The AMV and PDO spatial patterns in the forced ensemble and control are shown in Figs. S1 and S2 in the online supplemental material, respectively.

We compare composites that include years that are more than one standard deviation above and below the long-term mean of each index. The statistical significance of the anomalies between these two composites is calculated based on the likelihood of a random occurrence of the signal: the signals detected are compared to analogs obtained by first randomly sampling each index 1000 times and then repeating the same analysis; the 5th

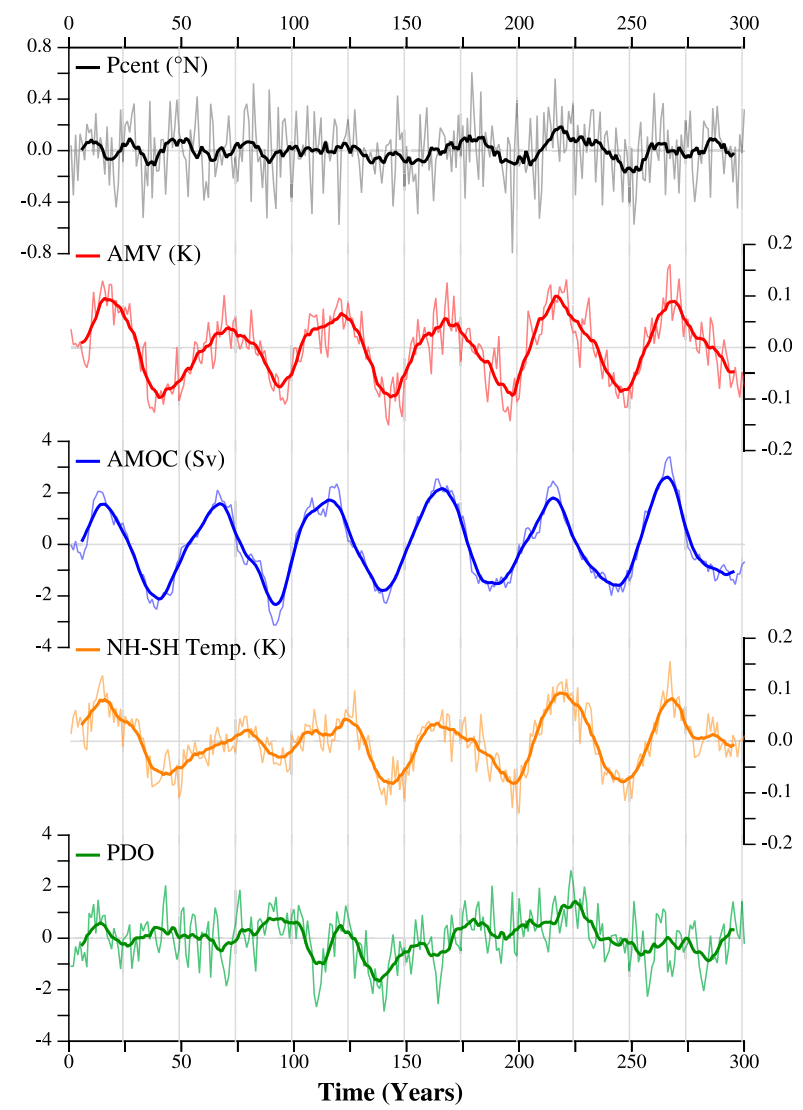

FIG. 1. Times series in the 10 -member ensemble mean of the forced simulations. See section 2 for definitions and details of the indices. Thin and thick lines are the yearly values and the 11-yr running mean, respectively.

and 95th percentiles of the empirical anomaly distribution set the confidence levels.

\section{Analysis of the model simulations}

\section{a. Forced ensemble}

The link between the ITCZ, AMV, and AMOC is first explored in the 10-member ensemble mean of the forced simulations. We focus on the ensemble mean since this helps increase the signal-to-noise ratio and thus allows one to characterize the forced variability more readily. In the ensemble mean, the Pcent, AMV, AMOC strength, and interhemispheric temperature difference all exhibit 50-yr periodicity following that of the imposed forcing (Fig. 1): the spectrum of these indices shows a prominent peak at a period of about 50 years that is statistically significant at the 5\% level (Fig. S3). There is strong covariability between the AMOC strength, AMV, and interhemispheric temperature difference on multidecadal time scales over the whole 

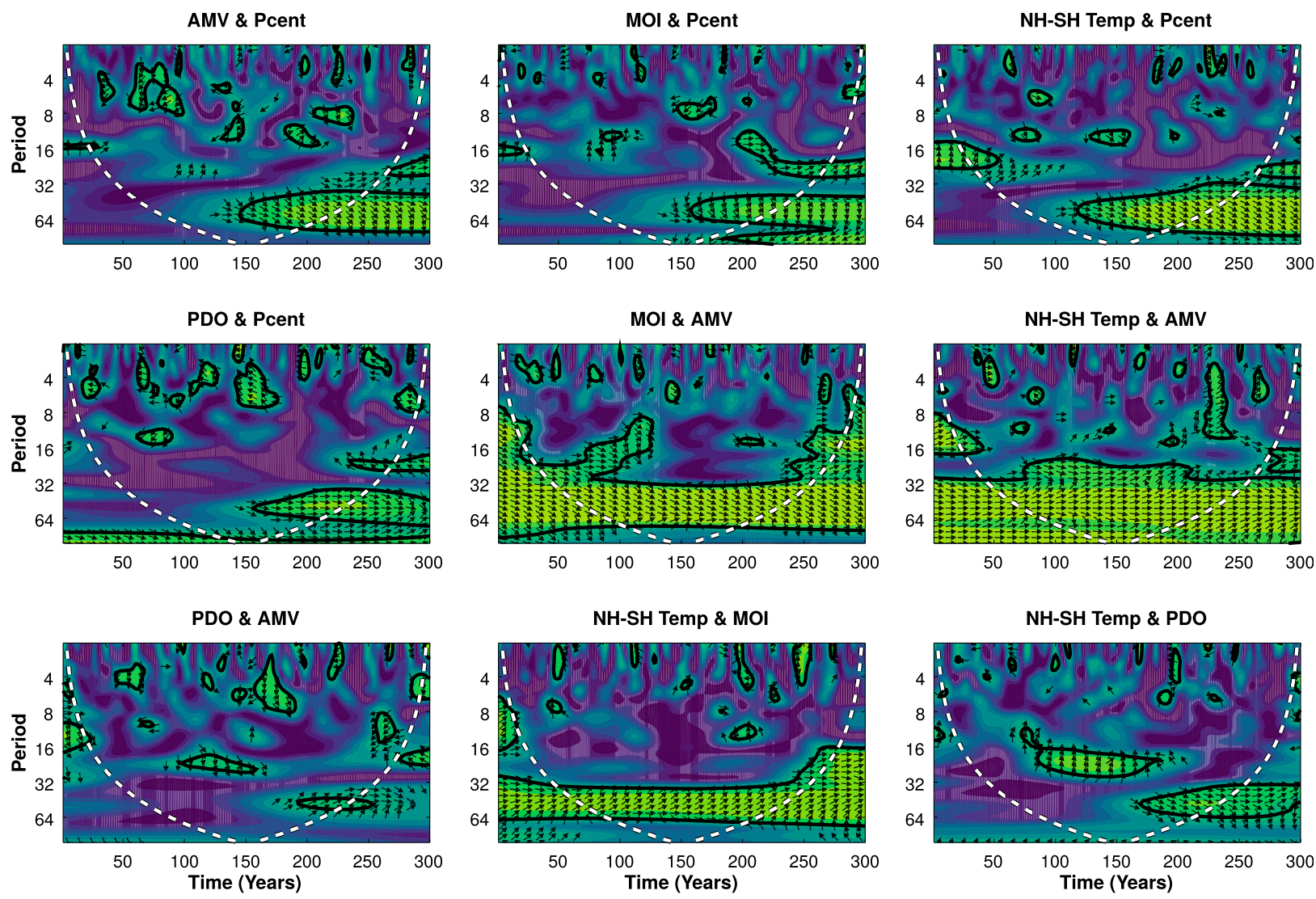

0

0.2

0.4

0.6

0.8

FIG. 2. Cross-wavelet coherence between the yearly indices in the forced ensemble (in Fig. 1). The first and second time series are indicated above each panel to help identify leads or lags between the two. Wavelet coherence highlights regions in time-frequency space with a large common power and consistent phase relationship between two time series, which suggests periods when there might exist causality between their underlying processes. Significant coherence values, however, do not necessarily mean actual causality. Color shading indicates the coherence strength, with green-yellow colors within black contours being statistically significant at the $5 \%$ level against red noise. The arrow direction indicates the phase relationship between the two wavelet transforms: arrows pointing right (left) indicate that the two series are in phase (out of phase), while arrows pointing down (up) indicate that the second series lags (leads) the first one, if the two series are positively correlated. The cone of influence (white dashed line) defines the area in which the border effect does not influence the wavelet spectra.

simulated period, and between these three indices and Pcent in the second half (green-yellow shading in Fig. 2). Furthermore, AMOC variability leads that of the AMV, interhemispheric temperature difference, and Pcent, while the AMV and temperature difference vary in phase and lead Pcent variability (arrows in Fig. 2; see also Fig. S2).

Precipitation anomaly patterns following a phase change of the AMOC and AMV are broadly similar and reflect an ITCZ shift (Figs. 3b,c). A strong AMOC and a warm AMV lead to a precipitation increase in most of the NH tropics, especially in the tropical North Atlantic and North Pacific and the Sahel, and a precipitation decrease most notably in Southeast Asia, the tropical South Pacific, Brazil, and the equatorial Atlantic. Such precipitation changes are further associated with an overall strengthening and weakening of the trade winds in the $\mathrm{SH}$ and $\mathrm{NH}$, respectively (arrows in Fig. 3), reflecting a northward shift of the Hadley circulation. Similarly, a northward ITCZ shift is also associated with a North Atlantic SST warming resembling a warm AMV phase and an AMOC-related warming (Fig. S1). Precipitation anomalies driven by the AMOC and AMV are similar to those of an ITCZ shift, although anomalies in the latter case are larger and more widespread in the northwestern and central tropical Pacific and less so in the tropical Atlantic, the Sahel, and South America (Figs. 3a-c). Regional mechanisms, such as the Bjerknes feedback (by which initial SST anomalies get amplified as they weaken the trade winds aloft; Bjerknes 1969), 


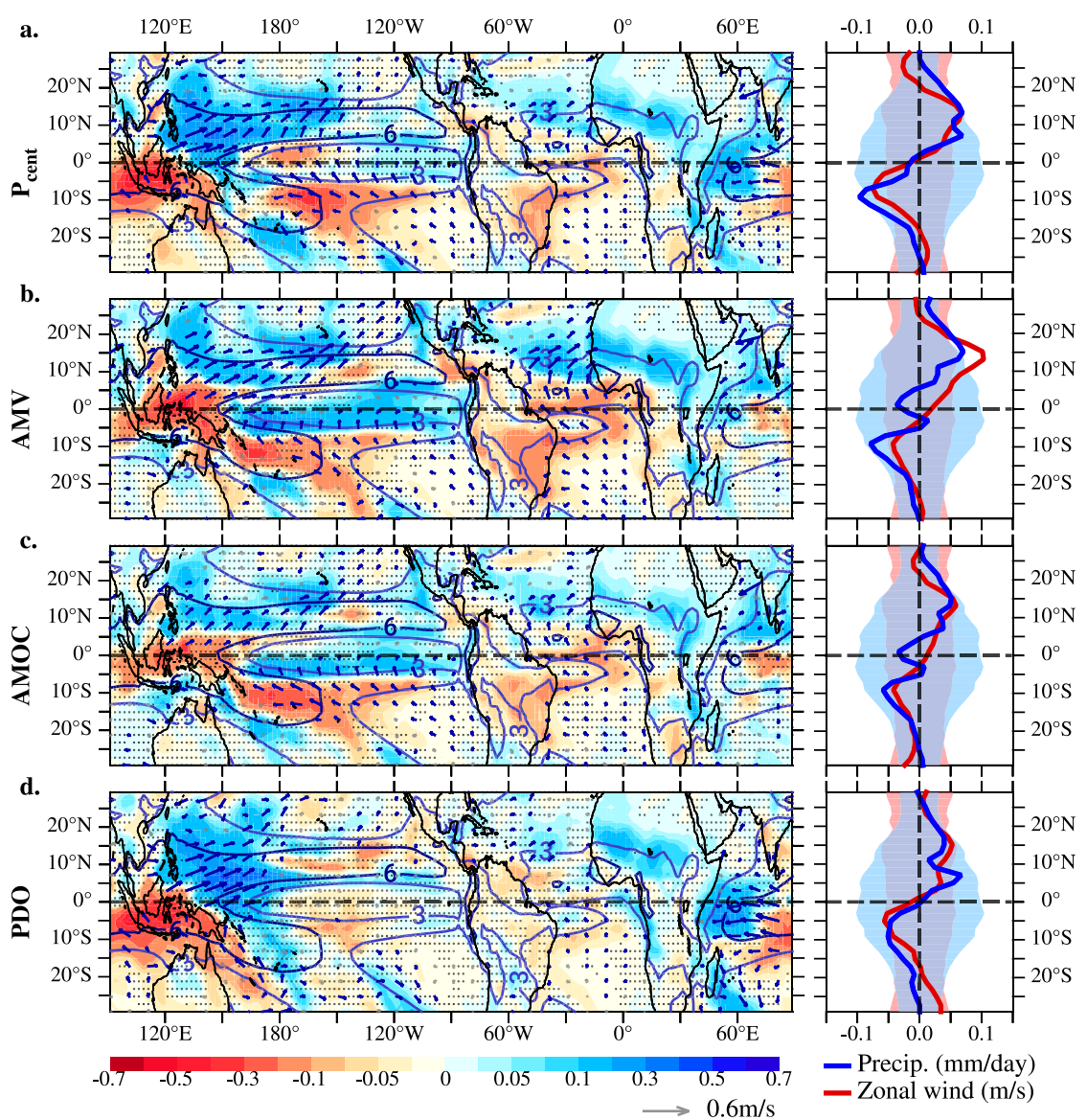

FIG. 3. (left) Anomalies in the annual-mean precipitation rate (shading; $\mathrm{mm} \mathrm{day}^{-1}$ ) and $1000-\mathrm{hPa}$ wind (arrows; $\mathrm{m} \mathrm{s}^{-1}$ ) between years above and below one standard deviation in the decadally smoothed indices (in Fig. 1) of the ensemble of forced simulations. Anomalies are calculated with the AMV and AMOC leading by 4 and 10 years, respectively, and the PDO lagging by 4 years (values derived from the cross-correlation profiles in Fig. S4) and only in the second half (years 151-300), when the Pcent, AMV, and AMOC show statistically significant coherence at multidecadal time scales (Fig. 2). Light and dark blue lines are the 3 and $6 \mathrm{~mm}$ day $^{-1}$ precipitation climatologies, respectively. Stippling masks statistically nonsignificant anomalies in precipitation at the $5 \%$ level, whereas blue arrows highlight statistically significant anomalies. (right) Zonally averaged anomalies in precipitation (blue) and wind (red) from the left panels. Blue and red shading respectively mask anomalies in precipitation and zonal wind that are nonsignificant at the $5 \%$ level.

might explain these differences, because a positive AMV phase would especially favor atmospheric convection in the tropical Atlantic. Despite these differences, both a warm AMV and a strong AMOC lead to a northward shift of the ITCZ and Hadley circulation of similar magnitude and shape in the zonal average (Fig. 3, right panels).

What mechanisms link oscillations in the AMOC, $\mathrm{AMV}$, interhemispheric temperature difference, and ITCZ? Periodicity in the four indices is rooted in the change in buoyancy flux forced by the NAO-derived oscillatory heat flux anomaly, especially in the Labrador Sea (Delworth and Zeng 2016). For example, for a negative downward flux anomaly the induced upperocean cooling enhances the oceanic deep mixing and thereby strengthens the AMOC and its associated poleward heat transport (Fig. 4, blue line). The latter warms the North Atlantic surface (positive AMV phase) in the following 3 years, as illustrated by the positive Atlantic ocean heat transport (OHT) anomaly that precedes a warm AMV (Fig. 4) and by the similarity in the SST pattern for a positive AMV and a strong AMOC (Fig. S1). The North Atlantic surface warming propagates to the troposphere aloft through anomalous airsea heat flux, especially at midlatitudes (not shown). This heating is quickly distributed zonally and vertically 

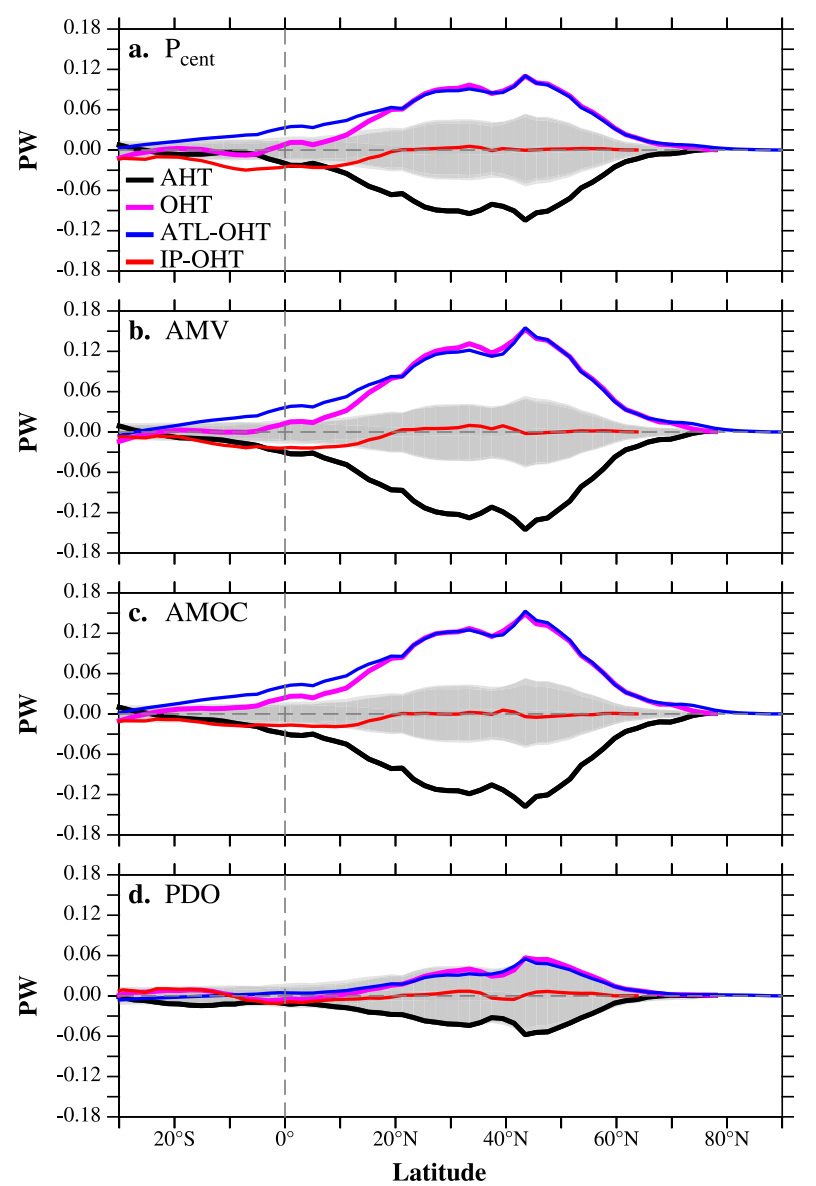

FIG. 4. As in Fig. 3, but for anomalies in the heat transport (PW) in the atmosphere (AHT; black line), the global ocean (OHT; pink), Atlantic Ocean (ATL-OHT; blue), and Indo-Pacific Ocean (IP-OHT; red) north of $30^{\circ} \mathrm{S}$ in the ensemble of forced simulations. Anomalies are calculated with the AMOC in phase, and the Pcent, AMV, and PDO lagging behind by 8,3 , and 10 years, respectively. For simplicity, gray shading is used to mask all anomalies nonsignificant at the $5 \%$ level in the heat transport components.

through transport and mixing by dominant westerly winds and eddies in the following years [as also shown in Chiang et al. (2003), Chiang and Bitz (2005), Cvijanovic and Chiang (2013), and Donohoe et al. (2013)]. Both atmospheric eddies propagating equatorward from midlatitudes (Chiang and Friedman 2012; Bischoff and Schneider 2014) and the ocean heat release in the tropics (e.g., Cvijanovic and Chiang 2013) contribute to the heating of the $\mathrm{NH}$ tropical atmosphere and hence to the equatorward propagation of the heating anomaly after a positive AMV following a strong AMOC. The overall result is a $\mathrm{NH}$ atmosphere warmer than the $\mathrm{SH}$ at most latitudes (a positive interhemispheric temperature differences in Figs. 1 and 5, where we show the anomaly patterns of the asymmetric component of the zonally averaged tropospheric temperature; see the caption of
Fig. 5 for more details). The NH atmosphere's tropical heating propagates quickly across the equator due to the near symmetry in tropical temperatures about the equator (Schneider et al. 2014) and thus induces a change in the cross-equatorial atmospheric heat transport (AHT; Fig. 4, black lines) to compensate for the $\mathrm{NH}$ heating anomaly. This is facilitated by a northward shift of the ITCZ and Hadley circulation (Figs. 1-4), thus explaining the link between changes in the AMOC strength, AMV, and Pcent. The OHT in the Pacific and Indian Oceans (Fig. 4, red lines) also contributes to the NH heating anomaly compensation by transporting heat southward across the equator as a result of the change in the wind-driven oceanic subtropical cells (Green and Marshall 2017). This chain of events is supported by the close correspondence between the anomaly patterns of the asymmetric component of the zonally averaged tropospheric temperature and of the heat transport related to a phase shift in the AMOC, AMV, and Pcent (Figs. 4 and 5).

The PDO shows synchronous coherence with the Pcent and lags behind changes in the AMV and interhemispheric temperature difference between years 150 and 300 on the time scales of the applied forcing (Fig. 2). This suggests that a positive PDO tends to develop after a positive AMV phase warms the $\mathrm{NH}$ and shifts the ITCZ northward (and vice versa). The PDO time series, however, shows no evident 50 -yr cycle imposed by the surface heat forcing and instead exhibits centennial oscillations between a positive phase and a negative phase (Fig. 1 and Fig. S3). Correlation coefficients between the PDO and AMV are relatively small at all lags (Fig. S4b). These results are different from those reported by Ruprich-Robert et al. (2017), in which a negative PDO develops after a warm AMV, and vice versa. They, however, used simulations with the same climate model (CM2.1) in which North Atlantic SSTs are continuously restored toward AMV anomalies over 10 years. Differences between their and our results might be caused by a larger amplitude in the tropical North Atlantic SSTs in the case in which they are restored compared to when they are induced by AMOC variations, thus resulting in a stronger teleconnection between the Atlantic and Pacific tropical atmosphere.

The patterns of anomalies in net precipitation, zonally averaged asymmetric temperature, and OHT and AHT (Figs. 3, 4, and 5, respectively) that precede the PDO by a few years (Fig. S4) are very similar to those related to an ITCZ-AMV shift. This reinforces our conclusion that a PDO shift tends to follow one in the ITCZ, or AMV, or in both, on multidecadal time scales in the forced ensemble. At such time scales, the PDO-ITCZ link therefore appears to be dominated by their response to the AMV. On 


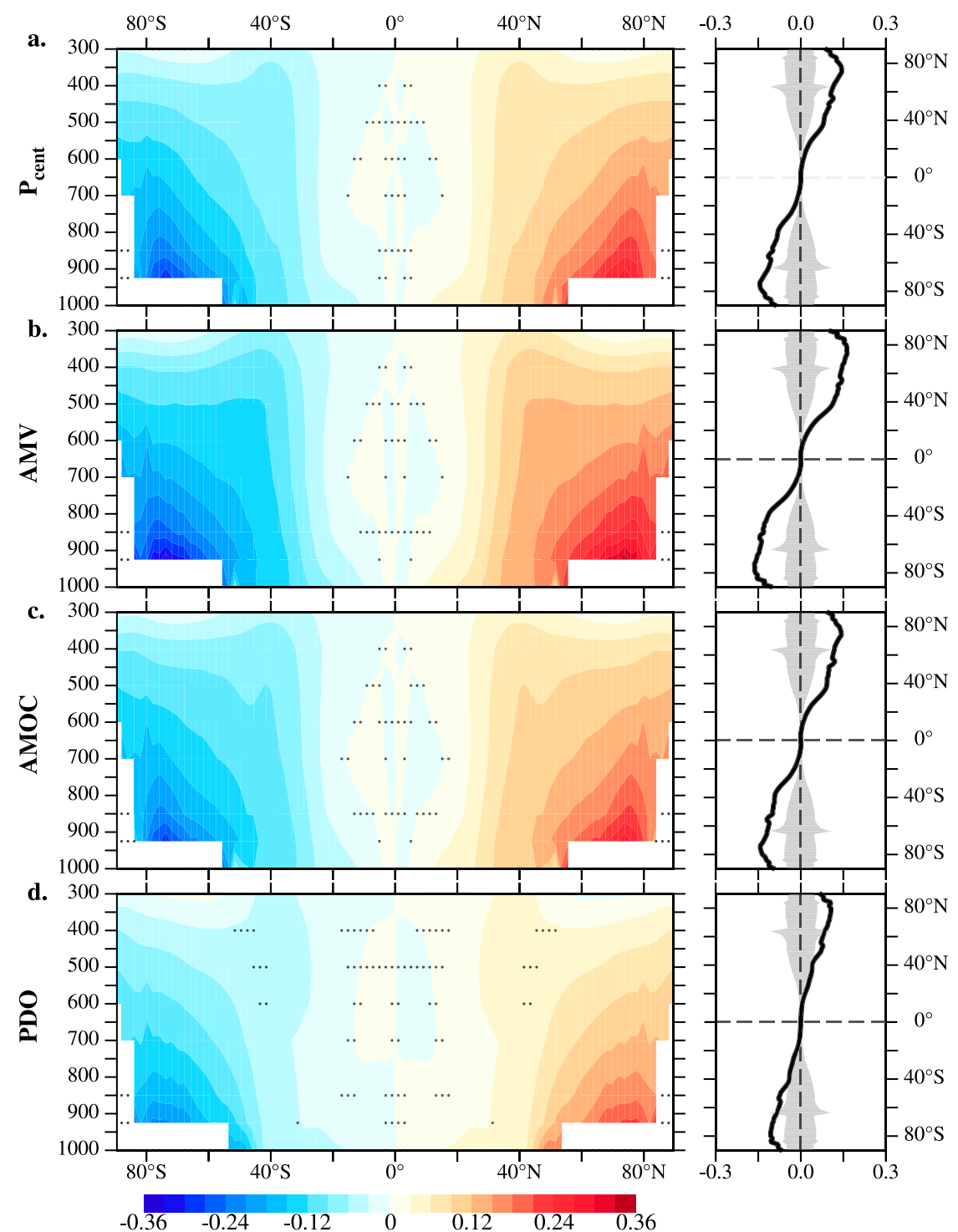

FIG. 5. As in Fig. 3, but for the asymmetric component of the zonally averaged atmospheric temperature $(\mathrm{K})$ in the ensemble of forced simulations. The AMV and AMOC lead the temperature anomalies by 1 and 5 years, respectively, and the Pcent and PDO lag behind by 3 and 5 years, respectively (values derived from the cross-correlation profiles in Fig. S4). The asymmetric component is calculated as $[T(y)-T(-y)] / 2$, where $y$ is the latitude. By construction, this component highlights the asymmetric pattern about the equator.

other time scales, a PDO phase shift is not robustly associated with an interhemispheric temperature anomaly or ITCZ shift (Fig. 2), thus relegating the PDO as a direct driver of variability in the meridional position of the ITCZ in the forced ensemble.

\section{b. Control simulation}

We extend our analysis to a 4000-yr control simulation with preindustrial forcing performed with the same climate model. Here, synchronous coherence between
AMOC and AMV variability, and between the latter and the interhemispheric temperature difference (indices in Fig. 6), extends over the 4000 years especially on multicentennial time scales (Fig. 7). The spectra of the AMOC, AMV, and interhemispheric temperature difference exhibit a strong peak centered at a period of about 250 years, which is statistically significant at the $5 \%$ level (Fig. S5). The AMV spectrum in the control shows a relative maximum on a time scale of 32-64 years (which is only statistically significant at the $10 \%$ level), 


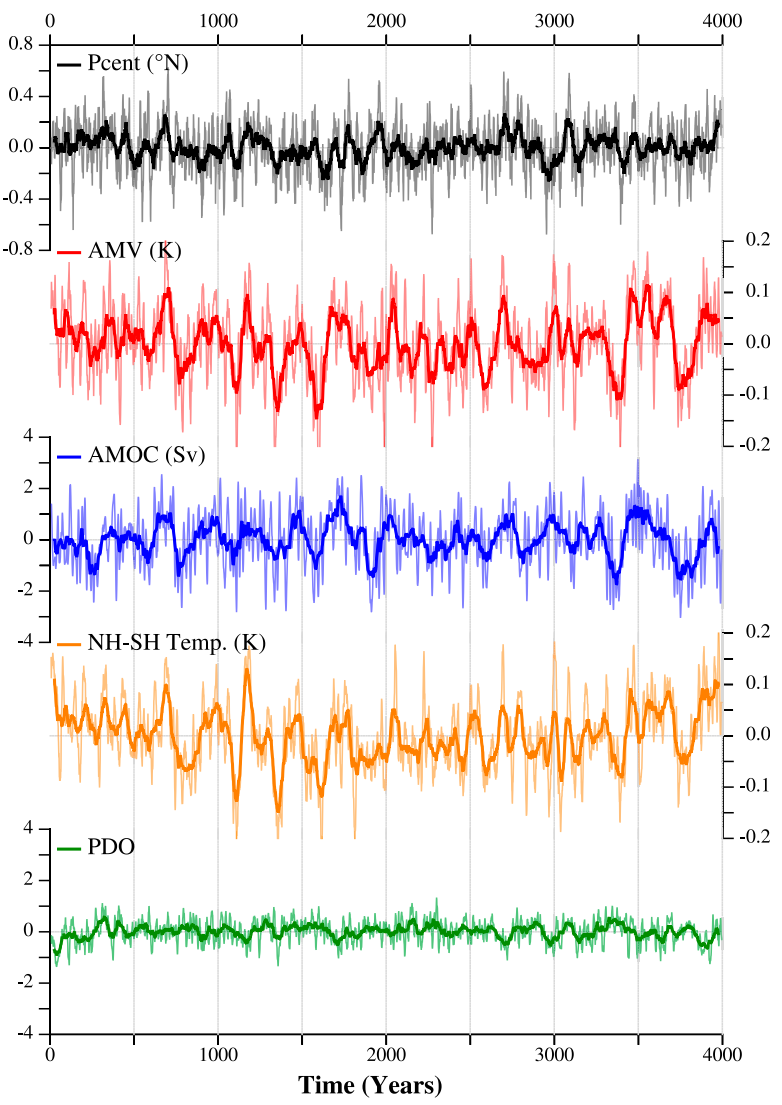

FIG. 6. Time series in the control, as in Fig. 1. Thin and thick lines are the 11- and the 51-yr running means, respectively.

similar to the time scale of 50-70 years in the observed AMV index (e.g., Frankcombe et al. 2010). The results in the control simulation support the connection between a strong AMOC and a warming of the North Atlantic SST (positive AMV) and, by extension, of the entire $\mathrm{NH}$, and vice versa.

Coherence between Pcent and AMV is intermittent in time in the control (Fig. 7). This suggests that the interhemispheric heating imbalance associated with an AMV phase shift is not always compensated by a change in the cross-equatorial AHT through an ITCZ shift; instead, during some periods other mechanisms more effectively compensate for the imbalance through a change in the top-of-the-atmosphere radiative balance, or ocean heat uptake, or both (e.g., Kang et al. 2008; Cvijanovic and Chiang 2013; Donohoe et al. 2013). Nonetheless, the Pcent, AMOC, and AMV variability show significant coherence on multicentennial time scales between years 500 and 2000 (Fig. 7), when the interhemispheric temperature difference shows some of the largest variations over the 4000 years of the control integration (Fig. 6). AMV and Pcent also exhibit intermittent coherence on decadal and multidecadal time scales between years 2000 and 4000 approximately (Fig. 7). Over all these periods, Pcent lags behind changes in AMOC and AMV by a few decades (arrows in Fig. 7). To focus on the most robust connection between AMOC, AMV, and Pcent on multicentennial time scales, we apply a bandpass filter with a period range between 200 and 300 years to all the data (filtered indices in Fig. S6) and analyze the 1500-yr-long period between years 500 and 2000 .

The anomaly patterns of the band-passed precipitation related to a strong AMOC and a warm AMV are very similar to that for a northward ITCZ shift (Fig. 8). They show a wetter western tropical North Pacific and central Pacific, North Atlantic, and the Sahel, and dryer Southeast Asia, northern Australia, equatorial central Pacific and Atlantic, and South America (Fig. 8). A northward ITCZ shift is also associated with an AMV-like North Atlantic SST warming (Fig. S2) and a widespread tropospheric NH warming (Fig. S8), which are in turn driven by a stronger AMOC and associated OHT (not shown), as in the ensemble mean of forced runs described above. The time scale of the AMOC-AMV-ITCZ link is, however, longer in the control than in the forced simulations: a maximum northward ITCZ shift occurs about 24 years later than a maximum positive AMV in the control, but only 4 years later in the forced case (Figs. S7 and S4).

PDO and Pcent show out-of-phase covariability only on multicentennial time scales, with a PDO warm phase following or lagging behind a northward ITCZ shift by about 250 years, and vice versa (Fig. 7). Nonetheless, the PDO does not show similar coherence with the interhemispheric temperature difference at such time scales (Fig. 7), indicating that the PDO does not induce an interhemispheric heating anomaly (Fig. S8) able to force a meridional ITCZ shift. In addition, the PDO and Pcent indices show no evident covariability on multicentennial time scales in the period 500-2000 years, in contrast to AMV and Pcent (Fig. 7). Phase changes in the PDO are not clearly connected to an ITCZ shift in precipitation (Fig. 8d) and its associated SST anomalies (Fig. S2) drive no significant interhemispheric temperature anomalies in the troposphere (Fig. S8d). These results reinforce the conclusion that the PDO-ITCZ connection is far less distinct than the AMV-ITCZ one.

\section{Discussion}

Both the 10-member ensemble mean of forced simulations and the control simulation show that the zonally averaged meridional position of the ITCZ is linked to the North Atlantic SST and, by extension, to AMOC variability. This linkage results from the interhemispheric atmospheric heating imbalance (Fig. 5 and Fig. S8) driven by a change in the Atlantic cross-equatorial OHT (Fig. 4) 

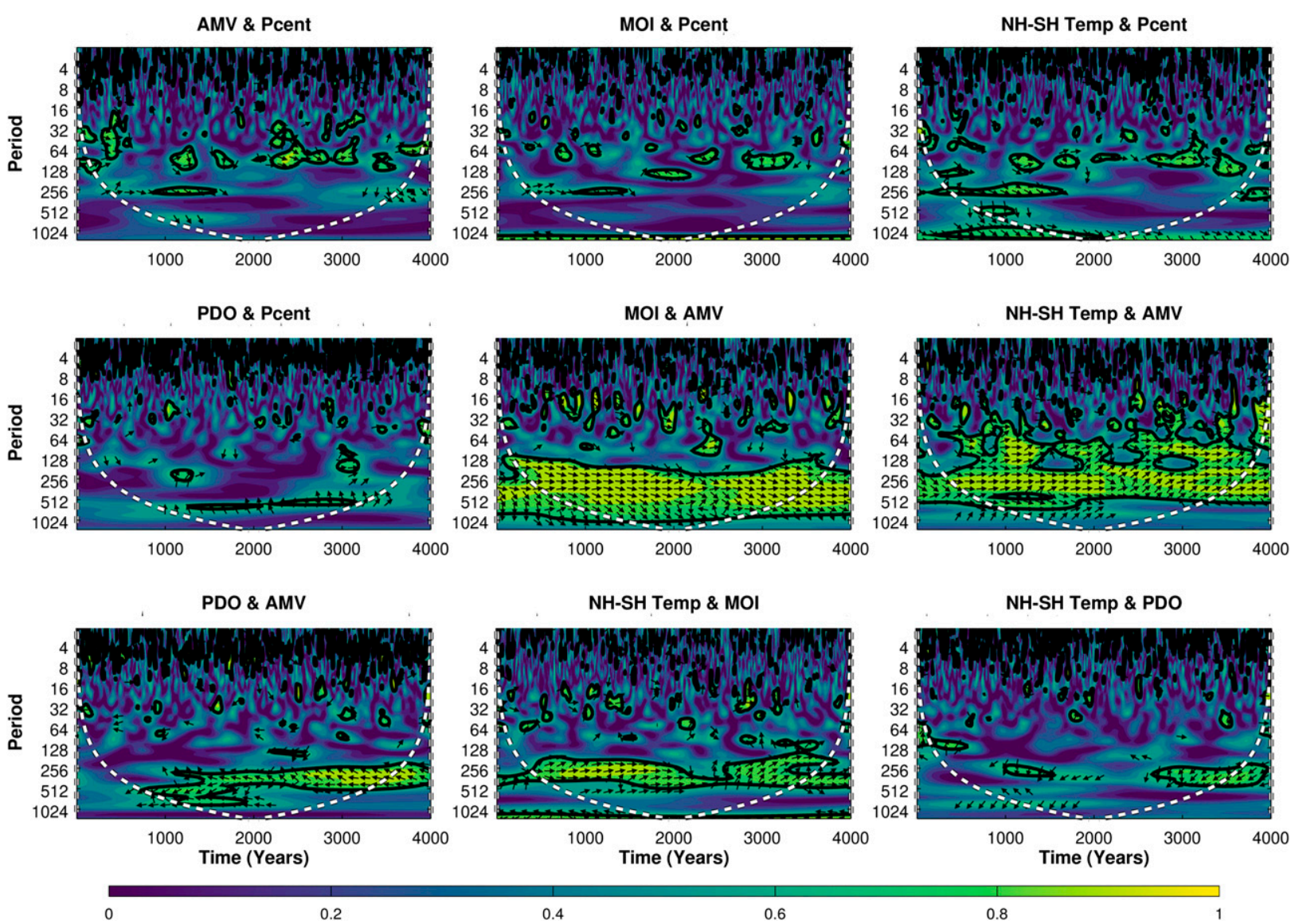

FIG. 7. As in Fig. 2, but for the indices in the control simulation (shown in Fig. 6).

impacting North Atlantic SSTs (Figs. S1 and S2). The NH heating anomaly is compensated by a meridional shift in the Hadley circulation and ITCZ (Figs. 3 and 8), which enhances the cross-equatorial AHT into the colder hemisphere (Fig. 4). This chain of events, however, only operates if the heating imbalance is not fully compensated by an adjustment in the top-of-the-atmosphere radiative flux or the ocean heat uptake, or both (e.g., Kang et al. 2008; Donohoe et al. 2013). This might explain why the linkage is not found on all time scales and over the whole period in the control.

Although simulated AMOC variability is also pronounced on 20-yr time scales in the control (Fig. S5), it is not associated with similar variability in the AMV and ITCZ (Fig. 7 and Fig. S5). On multicentennial time scales, AMOC variations in the control simulation of the CM2.1 model are driven by salinity anomalies propagating from the Southern Ocean to the subpolar North Atlantic, with the associated change in cross-equatorial Atlantic OHT inducing multicentennial North Atlantic SST anomalies (Delworth and Zeng 2012). Changes in the surface albedo of sea ice and low-level cloudiness help amplify such
AMOC-related SST variations (Fig. S2), thus leading to deeper, more global impacts on tropospheric temperatures (Fig. S8) (Delworth and Zeng 2012). We argue that such amplification is key to triggering ITCZ shifts on multicentennial time scales rather than on shorter ones in the control.

The forced simulations use the same model version as the control (GFDL CM2.1), and thus we expect these to show the same sort of internally generated multicentennial variability; this is, however, not resolved by the length of the integration in the forced runs and, even if it were, it would be averaged out in their ensemble mean. Therefore, the analysis instead focuses on the forced variability in the ensemble mean of the forced simulations, exploring linkages between the ITCZ, AMV, and AMOC from a different point of view. We find, nonetheless, that the mechanism linking the AMOC, AMV, and ITCZ is not fully active during the first 150 years in the ensemble mean of forced simulations (Fig. 2). This is suggestive of an initial period of adjustment in the top-ofthe-atmosphere net radiative flux, or ocean heat uptake, or both, which compensates for the forcing and is perhaps 


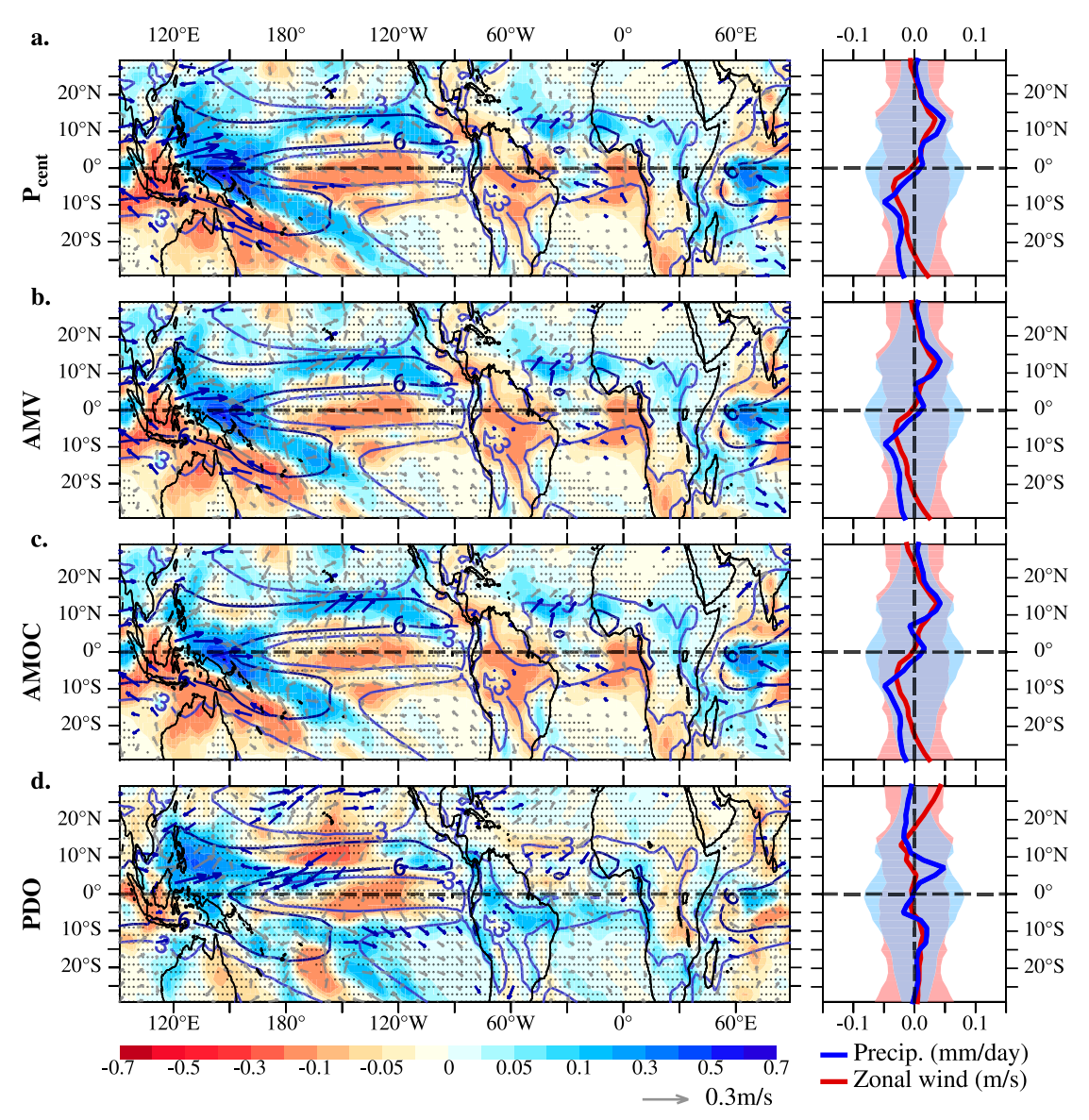

FIG. 8. As in Fig. 3, but for the band-passed indices in the control (see text for details; bandpass-filtered indices in Fig. S6). Calculations are carried out between years 500 and 2000, when the Pcent, AMV, and AMOC show coherence on centennial time scales (Fig. 7). Precipitation anomalies lag behind the AMV and the AMOC by 24 years (values derived from the cross-correlation profiles in Fig. S7). No lead or lag is applied to the PDO.

somewhat different in each ensemble member, causing the signal to be averaged out in the ensemble mean. Each ensemble member starts from a different point in the control simulation, to which a fairly modest perturbation is added (Delworth and Zeng 2016), and thus has a random phasing of internal variability. It appears to take some time before the NAO-related surface heat flux forcing is able to "sync up" the variability in the differing ensemble members. Furthermore, the linkage between the AMV and ITCZ might be related to the amplitude of the changes in the interhemispheric temperature differences: in the forced ensemble on multidecadal time scales they are almost as large as those in the control on multicentennial time scales. Regardless of the time scales or period, we find the meridional position of the ITCZ to be tied to changes in the AMOC through the AMV in both types of simulations (Figs. 2, 3, 7, and 8). Our model results thus support and expand those from the observations covering the twentieth century (Green et al. 2017).
Compared to observations, AMOC variations induced in the model result in relatively small SST variations in the North Atlantic (of an amplitude of about $0.4 \mathrm{~K}$ in observations; Ting et al. 2009) and about $0.2 \mathrm{~K}$ both in the control and ensemble mean; Fig. 1). Such relatively small variations might also explain the discontinuous connection between the AMOC, AMV, and ITCZ in the model. Perhaps SST changes in the North Atlantic are not large enough to trigger a long-lasting, global response in atmospheric temperature and tropical precipitation. A relatively muted response might also hamper detecting such connections in the observations (Green et al. 2017).

A similar linkage between the AMOC, AMV, and ITCZ can be found in the paleo-record, where the amplitude of the changes and, thus, the signal-to-noise ratio is indeed much larger. For example, an AMOC collapse and strong $\mathrm{NH}$ cooling support evidence of a southward ITCZ and Hadley circulation shift during Heinrich 
a.

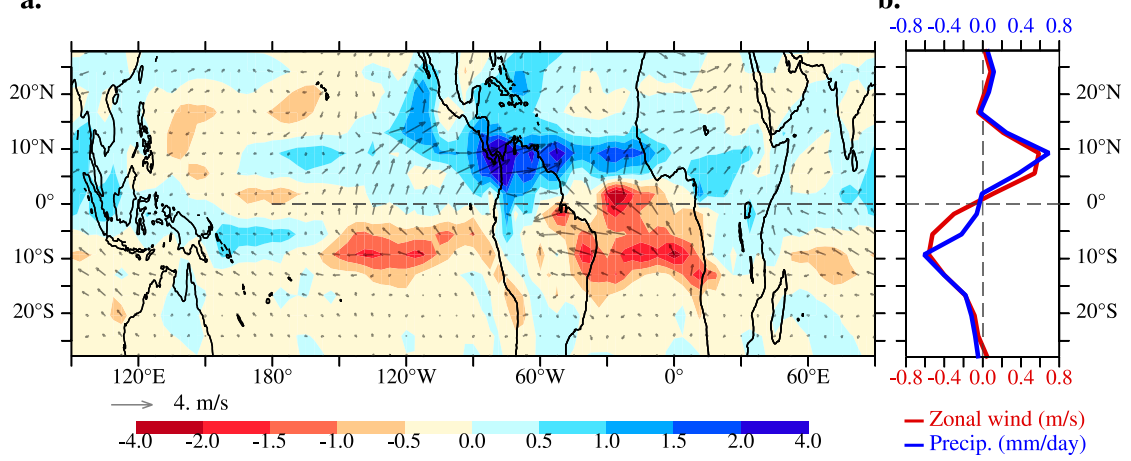

FIG. 9. (a) Anomalies in the annual mean precipitation rate (shading; $\mathrm{mm} \mathrm{day}^{-1}$ ) and nearsurface $(10 \mathrm{~m})$ winds between the Last Glacial Maximum (LGM) and the Heinrich Stadial 1 (HS1), averaged over the periods 20-21 and 15.5-16.5 kyr, respectively, in the TraCE-21ka simulation: the ITCZ is farther north during the LGM than during the HS1. Note that the shading color scale is adapted for a better view of the precipitation anomalies in the range of $\pm 2 \mathrm{~mm} \mathrm{day}^{-1}$. No significances are shown since almost all of the anomalies are statistically significant at the 5\% level (based on a two-tailed Student's $t$ test in which effective degrees of freedoms and serial autocorrelation are taken into account). (b) Zonally averaged anomalies in the precipitation rate (blue) and wind (red) from (a). Adapted from McGee et al. (2018a). events over the past glacial period (e.g., Lynch-Stieglitz 2017; McGee et al. 2014, 2018a). Figure 9 illustrates this link through anomalies in net precipitation and nearsurface wind between the Heinrich Event 1 and the Last Glacial Maximum in the TraCE-21ka simulation, a transient simulation of the last 21000 years (Liu et al. 2009). In this simulation, an anomalous freshwater flux is applied to the North Atlantic Ocean to trigger an AMOC shutdown. The large $\mathrm{NH}$ cooling associated with the reduction in the Atlantic cross-equatorial OHT forces a response in the ITCZ and Hadley circulation (McGee et al. 2018b), which permits an increase in the northward cross-equatorial AHT to compensate for the strong interhemispheric heating imbalance. This mechanism is essentially the same as the one which we have identified as operating in CM2.1 used here.

Although the zonally averaged precipitation anomalies of the strong AMOC, warm AMV, and northward ITCZ shift are relatively similar in the control and the ensemble mean of the forced simulations, the spatial pattern of precipitation anomalies differs between the two simulations (cf. Figs. 3 and 8). Moreover, both patterns are in turn different from each climatological mean (contours in Figs. 3 and 8). It is, however, important to note that precipitation anomalies develop on different time scales: multidecadal scales in the ensemble mean of the forced simulations, and multicentennial ones in the control. The regional pattern of the ITCZ shifts may thus depend on the time scale, in agreement with the results in Roberts et al. (2017). Precipitation anomalies in CM2.1 are also different from those found in models that simulate a transition from the Last Glacial Maximum to the Heinrich Stadial 1, as in the TraCE-21ka simulation performed with the CCM3 model shown in Fig. 9. This suggests that regional precipitation anomalies related to an ITCZ shift may also be model dependent.

In addition to the spatial pattern, the response time of the ITCZ to AMOC and AMV variations is also different in the control and the forced ensemble. In the control, the cross-equatorial AHT and the associated ITCZ shift take longer than in the forced ensemble to respond to the interhemispheric heating imbalance. This might be related to the time scale by which other processes such as a change in the top-of-the-atmosphere energy flux take to compensate for the interhemispheric heating imbalance We propose that, only when the interhemispheric heating imbalance is large enough for it not to be fully compensated by these other processes, does an anomalous cross-equatorial AHT and/or OHT get triggered. This then shifts the ITCZ and Hadley circulation meridionally, yet delayed with respect to the onset of the heating imbalance. Furthermore, changes in the climate due to AMV phase and ITCZ shift might modify (decrease) the effectiveness of the other processes compensating for the heating imbalance (e.g., by changing the albedo or water vapor content of the atmosphere), increasing the role of the cross-equatorial AHT in its compensation and hence shifting the ITCZ farther (even if the heating imbalance has already started to get dampened). This would explain why the ITCZ shifts peaks some years later than the AMV and the interhemispheric temperature difference. We also note 
that, somehow, the lag between the AMV and ITCZ appears to be related to the time scale of the linkage by a factor of 10 (50-yr time scale and 4-yr lag in the ensemble mean of the forced simulations, and 250-yr time scale and 24-yr lag in the control; Figs. 3 and 8). These connections and delay will require future investigations.

\section{Conclusions}

We have investigated the linkage between variability in the tropical SST in the North Atlantic and North Pacific, characterized by the AMV and PDO, AMOC, and meridional position of the ITCZ in two sorts of simulations with GFDL's CM2.1: an ensemble of 10 simulations forced with a 50-yr-long oscillatory anomaly of the North Atlantic surface heat flux related to the NAO, and a 4000-yr-long preindustrial (with 1860s forcing conditions) control simulation. Our results indicate the following:

1) Both in the ensemble mean of the forced simulations and the control, changes in the cross-equatorial OHT driven by the AMOC lead to changes in the North Atlantic SST that shift the AMV phase. This, in turn, forces an interhemispheric heating imbalance that is compensated by a meridional shift in the Hadley circulation and the ITCZ meridional position connected to widespread, global changes in the tropical precipitation. This result provides a clear link between the AMOC, AMV, and ITCZ variability. This link operates on multidecadal time scales in the forced ensemble, related to the imposed surface heat flux, and mainly on multicentennial time scales in the control, with a shorter lag between the peaks in the AMV and ITCZ variability in the forced ensemble than in the control (4 and 24 years, respectively). In addition, the pattern of tropical precipitation anomalies is different between the control and the forced ensemble for a similar zonally averaged ITCZ shift, which suggests a dependence on the time scale. Our results thus offer support for an AMV-ITCZ link over the twentieth century hinted at in observations and further show it to be driven by AMOC variability in this coupled climate model.

2) In contrast to the AMV, the forced ensemble and the control show no ITCZ shift following a change in the PDO. This is consistent with point 1 , in that the PDO has a negligible impact on oceanic and atmospheric cross-equatorial heat transport and on the atmospheric interhemispheric energy balance.

Acknowledgments. E. M.-C. and J. M. acknowledge support from NOAA Award NA16OAR4310177.

\section{REFERENCES}

Bischoff, T., and T. Schneider, 2014: Energetic constraints on the position of the intertropical convergence zone. J. Climate, 27, 4937-4951, https://doi.org/10.1175/JCLI-D-13-00650.1.

Bjerknes, J., 1969: Atmospheric teleconnections from the equatorial Pacific. Mon. Wea. Rev., 97, 163-172, https://doi.org/10.1175/ 1520-0493(1969)097<0163:ATFTEP>2.3.CO;2.

Broccoli, A. J., K. A. Dahl, and R. J. Stouffer, 2006: Response of the ITCZ to Northern Hemisphere cooling. Geophys. Res. Lett., 33, L01702, https://doi.org/10.1029/2005GL024546.

Buckley, M., and J. Marshall, 2016: Observations, inferences, and mechanisms of the Atlantic meridional overturning circulation: A review. Rev. Geophys., 54, 5-63, https://doi.org/10.1002/2015RG000493.

Chiang, J. C., and C. M. Bitz, 2005: Influence of high latitude ice cover on the marine Intertropical Convergence Zone. Climate Dyn., 25, 477-496, https://doi.org/10.1007/s00382-005-0040-5.

_ spheric thermal gradients, and tropical climate change. Annu. Rev. Earth Planet. Sci., 40, 383-412, https://doi.org/10.1146/ annurev-earth-042711-105545.

_ M. Biasutti, and D. S. Battisti, 2003: Sensitivity of the Atlantic intertropical convergence zone to Last Glacial Maximum boundary conditions. Paleoceanography, 18, 1094, https:// doi.org/10.1029/2003PA000916.

Cvijanovic, I., and J. C. H. Chiang, 2013: Global energy budget changes to high latitude North Atlantic cooling and the tropical ITCZ response. Climate Dyn., 40, 1435-1452, https:// doi.org/10.1007/s00382-012-1482-1.

Delworth, T. L., and F. Zeng, 2012: Multicentennial variability of the Atlantic meridional overturning circulation and its climatic influence in a 4000 year simulation of the GFDL CM2.1 climate model. Geophys. Res. Lett., 39, L13702, https://doi.org/ 10.1029/2012GL052107.

— on climate through its influence on the Atlantic meridional overturning circulation. J. Climate, 29, 941-962, https://doi.org/ 10.1175/JCLI-D-15-0396.1.

— models. Part I: Formulation and simulation characteristics. J. Climate, 19, 643-674, https://doi.org/10.1175/JCLI3629.1.

Donohoe, A., J. Marshall, D. Ferreira, and D. McGee, 2013: The relationship between ITCZ location and cross-equatorial atmospheric heat transport: From the seasonal cycle to the Last Glacial Maximum. J. Climate, 26, 3597-3618, https://doi.org/ 10.1175/JCLI-D-12-00467.1.

Ferrari, R., and D. Ferreira, 2011: What processes drive the ocean heat transport? Ocean Modell., 38, 171-186, https://doi.org/ 10.1016/j.ocemod.2011.02.013.

Folland, C. K., A. W. Colman, D. P. Rowell, and M. K. Davey, 2001: Predictability of northeast Brazil rainfall and real-time forecast skill, 1987-98. J. Climate, 14, 1937-1958, https://doi.org/10.1175/ 1520-0442(2001)014<1937:PONBRA>2.0.CO;2.

Frankcombe, L. M., A. von der Heydt, and H. A. Dijkstra, 2010: North Atlantic multidecadal climate variability: An investigation of dominant time scales and processes. J. Climate, 23, 3626-3638, https://doi.org/10.1175/2010JCLI3471.1.

Frierson, D. M. W., and Y.-T. Hwang, 2012: Extratropical influence on ITCZ shifts in slab ocean simulations of global warming. J. Climate, 25, 720-733, https://doi.org/10.1175/JCLI-D-11-00116.1.

- , and Coauthors, 2013: Contribution of ocean overturning circulation to tropical rainfall peak in the Northern Hemisphere. Nat. Geosci., 6, 940-944, https://doi.org/10.1038/ngeo1987. 
Green, B., and J. Marshall, 2017: Coupling of trade winds with ocean circulation damps ITCZ shifts. J. Climate, 30, 43954411, https://doi.org/10.1175/JCLI-D-16-0818.1.

— _ _ and A. Donohoe, 2017: Twentieth century correlations between extratropical SST variability and ITCZ shifts. Geophys. Res. Lett., 44, 9039-9047, https://doi.org/10.1002/2017GL075044.

Kang, S. M., I. M. Held, D. M. Frierson, and M. Zhao, 2008: The response of the ITCZ to extratropical thermal forcing: Idealized slab-ocean experiments with a GCM. J. Climate, 21, 35213532, https://doi.org/10.1175/2007JCLI2146.1.

Kerr, R. A., 2000: A North Atlantic climate pacemaker for the centuries. Science, 288, 1984-1985, https://doi.org/10.1126/ science.288.5473.1984.

Liu, Z., 2012: Dynamics of interdecadal climate variability: A historical perspective. J. Climate, 25, 1963-1995, https://doi.org/ 10.1175/2011JCLI3980.1.

— , and Coauthors, 2009: Transient simulation of last deglaciation with a new mechanism for Bølling-Allerød warming. Science, 325, 310-314, https://doi.org/10.1126/science.1171041.

Lynch-Stieglitz, J., 2017: The Atlantic meridional overturning circulation and abrupt climate change. Annu. Rev. Mar. Sci., 9, 83104, https://doi.org/10.1146/annurev-marine-010816-060415.

Mantua, N. J., and S. R. Hare, 2002: The Pacific decadal oscillation. J. Oceanogr., 58, 35-44, https://doi.org/10.1023/A:1015820616384.

$\longrightarrow,-$ _ Y. Zhang, J. M. Wallace, and R. C. Francis, 1997: A Pacific interdecadal climate oscillation with impacts on salmon production. Bull. Amer. Meteor. Soc., 78, 1069-1079, https://doi.org/ 10.1175/1520-0477(1997)078<1069:APICOW>2.0.CO;2.

Marshall, J., Donohoe, A., D. Ferreira, and D. McGee, 2014: The ocean's role in setting the mean position of the Inter-Tropical Convergence Zone. Climate Dyn., 42, 1967-1979, https:/doi.org/ 10.1007/s00382-013-1767-z.

McGee, D., A. Donohoe, J. Marshall and D. Ferreira, 2014: Changes in ITCZ location and cross-equatorial heat transport at the Last Glacial Maximum, Heinrich Stadial 1, and the midHolocene. Earth Planet. Sci. Lett., 390, 69-79, https://doi.org/ 10.1016/j.epsl.2013.12.043.

— , E. Moreno-Chamarro, B. Green, J. Marshall, E. Galbraith, and L. Bradtmiller, 2018a: Hemispherically asymmetric trade wind changes as signatures of past ITCZ shifts. Quat. Sci. Rev., 180, 214-228, https://doi.org/10.1016/j.quascirev.2017.11.020.

,-- J. Marshall, and E. D. Galbraith, 2018b: Western U.S. lake expansions during Heinrich stadials linked to Pacific Hadley circulation. Sci. Adv., 4, eaav0118, https://doi.org/ 10.1126/SCIADV.AAV0118.

Mohino, E., S. Janicot, and J. Bader, 2011: Sahel rainfall and decadal to multi-decadal sea surface temperature variability.
Climate Dyn., 37, 419-440, https://doi.org/10.1007/s00382-0100867-2.

Newman, M., and Coauthors, 2016: The Pacific decadal oscillation, revisited. J. Climate, 29, 4399-4427, https://doi.org/10.1175/ JCLI-D-15-0508.1.

Roberts, W. H., P. J. Valdes, and J. S. Singarayer, 2017: Can energy fluxes be used to interpret glacial/interglacial precipitation changes in the tropics? Geophys. Res. Lett., 44, 6373-6382, https://doi.org/10.1002/2017GL073103.

Ruprich-Robert, Y., R. Msadek, F. Castruccio, S. Yeager, T. Delworth, and G. Danabasoglu, 2017: Assessing the climate impacts of the observed Atlantic multidecadal variability using the GFDL CM2.1 and NCAR CESM1 global coupled models. J. Climate, 30, 2785-2810, https://doi.org/10.1175/ JCLI-D-16-0127.1.

Schneider, T., T. Bischoff, and G. H. Haug, 2014: Migrations and dynamics of the intertropical convergence zone. Nature, 513, 45-53, https://doi.org/10.1038/nature13636.

Sun, C., J. Li, F.-F. Jin, and R. Ding, 2013: Sea surface temperature inter-hemispheric dipole and its relation to tropical precipitation. Environ. Res. Lett., 8, 044006, https://doi.org/10.1088/1748-9326/ 8/4/044006.

Ting, M., Y. Kushnir, R. Seager, and C. Li, 2009: Forced and internal twentieth-century SST trends in the North Atlantic. J. Climate, 22, 1469-1481, https://doi.org/10.1175/2008JCLI2561.1.

Trenberth, K. E., and J. M. Caron, 2001: Estimates of meridional atmosphere and ocean heat transports. J. Climate, 14, 34333443, https://doi.org/10.1175/1520-0442(2001)014<3433: EOMAAO $>2.0 . \mathrm{CO} ; 2$.

, and D. J. Shea, 2006: Atlantic hurricanes and natural variability in 2005. Geophys. Res. Lett., 33, L12704, https://doi.org/ 10.1029/2006GL026894.

Tulloch, R., and J. Marshall, 2012: Exploring mechanisms of variability and predictability of Atlantic meridional overturning circulation in two coupled climate models. J. Climate, 25, 4067-4080, https://doi.org/10.1175/JCLI-D-11-00460.1.

Vellinga, M., and P. Wu, 2004: Low-latitude freshwater influence on centennial variability of the Atlantic thermohaline circulation. J. Climate, 17, 4498-4511, https://doi.org/10.1175/ 3219.1.

Zhang, R., and T. L. Delworth, 2005: Simulated tropical response to a substantial weakening of the Atlantic thermohaline circulation. J. Climate, 18, 1853-1860, https://doi.org/10.1175/ JCLI3460.1.

_, and - 2006: Impact of Atlantic multidecadal oscillations on India/Sahel rainfall and Atlantic hurricanes. Geophys. Res. Lett., 33, L17712, https://doi.org/10.1029/2006GL026267. 